\title{
NEOTECTÔNICA DA REGIÃO DO ALTO ESTRUTURAL DE QUELUZ (SP-RJ, BRASIL)
}

\author{
ELIZETE DOMINGUES SALVADOR \& CLÁUDIO RICCOMINI
}

\begin{abstract}
NEOTECTONICS OF THE REGION OF THE QUELUZ STRUCTURAL HIGH (SP-RJ,
BRAZIL) The region of the Paraiba do Sul River Valley between the cities of Cruzeiro (São Paulo) and Itatiaia (Rio de Janeiro), in Southeastern Brazil, comprises the eastern and western terminations, respectively, of the Cenozoic Taubate and Resende rift basins, as well as the Precambrian terranes of the Queluz Structural High separating these basins, and includes much evidence of recurrent or resurgent tectonic movements that have been active until recent times.

The morphostructural analysis of this region, combined with the characterization of the Quaternary sedimentary deposits and britfle tectonic structures, nas permitted the recognition of tferee phases of neotectonic movements. The oldest movements were related to a NW-SE compressive stress field, during the Pleistocene, associated with an E-W right-lateral transcurrent binary. The structures related to this phase affected colluvium and stone-line deposits, which are often overthrust by bloeks of basement rocks along faults trending NE to ENE.

Probably in the begining of the Holocene the stress regime changed to an E-W (WNW-ESE) extension, responsible for the generation of $\mathrm{N}-\mathrm{S}$-trending grabens with syntectonic sedimentary filling.

Finally, a new change in the stress field is recorded by conspicuous and widespread families of shear joints,

systematically orientated ENE and WNW, that affect colluvium, colhiviunvalluvium and alluvium deposits. The

accute bissectrix of the families of joints indicate an E-W direction of compression.

The reliability of the neotectonic data presented in this study and the proposed neotectonic model are particularly significant due to important human activities in the region, including such major engineering projects as a radioactive fuel factory, a hydroelectric power station and reservoir as well as a nuclear power plant.
\end{abstract}

Keywords: neotectonics, Paraíba do Sul River Valley, Cenozoic deposits

RESUMO A região do Vale do Rio Paraíba do Sul localizada entre Cruzeiro (SP) e Itatiaia (RJ), compreendendo o extremo leste da Bacia de Taubaté, oeste da Bacia de Resende, bem como o terreno constituído por rochas do embasamento pré-cambriano que separa estas bacias cenozóicas, o denominado Alto Estrutural de Queluz, encerra numerosas evidências de movimentos tectônicos recorrentes, ativos até os tempos recentes. A análise morfoestrutural, em conjunto com a caracterização dos depósitos sedimentares e das estruturas de caráter rúptil, permitiu o reconhecimento de três fases de movimentações neotectônicas.

Estas movimentacões estariam relacionadas inicialmente a esforços compressivos pleistocênicos orientados segundo NW-SE, associadas a um binário transcorrente dextral de direção E-W. As estruturas relacionadas a esta fase afetam depósitos coluviais e linhas de seixos, por vezes cavalgados por blocos de rochas do embasamento, ao longo de falhas de direções preferenciais NE a ENE. Posteriormente, uma mudança do regime de esforços foi assinalada durante 0 Holoceno, passando estes a extensionais, com direcões E-W (WNW-ESE). Esta fase é responsável pela geração de feições marcantes no relevo, como grabens de direção N-S, que embutem pacotes sedimentares com espessuras superiores a trinta metros. Finalmente, famílias de juntas conjugadas, de direções ENE e WNW, seccionando depósitos coluviais, colúvio-aluviais e aluviais, registrariam nova mudança no regime de esforços durante o Holoceno, agora compressivos, de direção E-W.

$\mathrm{O}$ quadro neotectônico já estabelecido é relevante em termos da estabilidade geológica da região, onde estão instaladas grandes obras de engenharia, incluindo uma central nuclear.

Palavras-chaves: neotectônica, Vale do Rio Paraíba do Sul, depósitos cenozóicos.

INTRODUÇÃO A ocorrência de terremotos de grande magnitude, mesmo em porções da crosta continental intraplaca, admitidas como as mais estáveis, vem tornando crescente a preocupação quanto à estabilidade geológica regional e suas implicações para a atividade humana, em especial a implantação de grandes obras de engenharia.

A incidência de abalos sísmicos em zonas sismogênicas como a do sudeste do Brasil, região de intensa ocupação, com numerosas instalações hidrelétricas e uma central nuclear, favoreceu o desenvolvimento de estudos visando o estabelecimento das relações entre a tectônica e a sismicidade.

Na porção leste do Estado de São Paulo, sul de Minas Gerais e oeste do Rio de Janeiro, levantamentos específicos foram realizados há cerca de 10 anos para as instalações da Usina de Angra dos Reis. Àquela época, as investigações não apontaram a existência de indícios de movimentos mais recentes do que 1,4-1,7 Ma (IPT 1983). Entretanto, a continuidade dos trabalhos (v.g. Riccomini 1989, 1995, Riccomini et al 1989,1991a, Hasui 1990,Saadi et al 1991, Salvador 1994) permitiu a verificação de um número crescente de indicações de atividades dessa natureza. Em particular, para a área limítrofe dos estados de São Paulo e Rio de Janeiro, no âmbito do denominado Alto Estrutural de Queluz, anteriormente designado de Soleira de Queluz por Freitas (1956), feição estrutural positiva que separa as bacias de Resende e Taubaté, vêm sendo encontradas várias evidências de atividade tectónica recente.

$\mathrm{O}$ interesse sobre as condições de estabilidade dessa área é crescente desde a implantação da Barragem do Funil, nas proximidades da Bacia de Resende e da Usina Nuclear de Angra dos Reis, na praia de Itaorna. Para a Barragem do Funil, que contempla um dique de terra e barragem de concreto em duplo arco, construída na década de 60 , devem ser adequadamente analisadas as condições de segurança da população situada no trecho do Rio Paraíba do Sul, a jusante da obra. De grande relevância é também a localização da Usina Nuclear de Angra dos Reis, que deve satisfazer as condições do U.S. Regulatory Guide, formulado em 1979, pelo qual as centrais

* - Programa de Pós-Graduação em Geologia Sedimentar, Instituto de Geociências, Universidade de São Paulo e Bolsista de Mestrado da Fundação de Amparo à Pesquisa do Estado de São Paulo, e-mail. salvador@usp.br

** - Instituto de Geociências, Universidade de São Paulo e Bolsista de Pesquisa do Conselho Nacional de Desenvolvimento Científico e Tecnológico - Caixa Postal 11.348, 05422-970, São Paulo, SP, Brasil - FAX: 55-011-818.4129, e-mail: riccomin@usp.br 
nucleares devem estar situadas em regiões sem movimentações tectônicas recentes (dentro do limite de detecção pelo método $\mathrm{C}^{14}$, aproximadamente 30.000 anos) ou recorrentes (nos últimos 500.000 anos) em uma área de $320 \mathrm{~km}$ de raio. Está também instalada na área estudada a Fábrica de Elementos Combustíveis, na localidade de Engenheiro Passos, onde a possibilidade de contaminação dos aquíferos em zonas fraturadas constitui aspecto merecedor dos devidos cuidados.

Pretendeu-se assim, através deste estudo, chegar-se à definição e caracterização dos movimentos tectônicos ocorrentes a partir do Mioceno Superior na área em foco, aqui entendidos como movimentos neotectônicos, bem como a relação das estruturas recentes, seus condicionantes estruturais mais antigos, reativações sucessivas e registros sedimentares associados. No Brasil, as pesquisas desta natureza vêm sendo ainda executadas de forma limitada, visando, sobretudo, a caracterização preliminar da estabilidade geológica de determinadas regiões.

No que diz respeito ao conceito de Neotectônica, vale apontar que o termo foi inicialmente empregado por Obruchev (1948) a fim de designar "os movimentos tectônicos recentes ocorridos no fim do Terciário e início do Quaternário, os quais tomaram um papel decisivo na formação da topografia contemporânea", com uma conotação essencialmente voltada para os movimentos verticais. Com a evolução dos conhecimentos da Geotectônica, inúmeras modificações foram realizadas, por diversos autores, sempre em busca de uma definição mais coerente com os modernos conceitos da Tectônica de Placas.

A moderna definição de Neotectônica têm sido objeto de várias discussões, não existindo ainda um consenso geral. A Comissão de Neotectônica da INQUA (International Union for Quaternary Research) (e.g. Mörner 1989), se refere à Neotectônica como "qualquer movimento da Terra ou deformação do nível de referência geodésico, seus mecanismos, sua origem (não importando o quão antiga esta seja), suas implicações práticas e suas extrapolações futuras". Ainda de acordo com a INQUA, a Neotectônica não possuiria vínculo cronológico, incluindo toda a escala de tempo dos movimentos, desde os instantâneos (sismos), até 10 anos, caso necessário para permitir o entendimento da origem do movimento registrado. Esta é a definição admitida para os fins deste estudo. Em trabalho mais recente, Mörner (1993) sugere que o uso do termo Neotectônica deveria ser restrito a fenômenos que tenham ocorrido nos últimos 2,5-3,0 Ma, iniciados com a reorganização tectônica geral que teria ocorrido neste período.

Os métodos de estudo compreenderam a análise estratigráfica, estrutural e de mapas morfométricos. Mapas morfotectônicos para a análise neotectônica vêm sendo empregados desde os trabalhos de Filosofov (1960 apud Jaim 1980). Este método vem sendo aprimorado e outros tipos de técnicas morfométricas vem sendo desenvolvidas, utilizando-se principalmente parâmetros de drenagem e relevo, gradientes de vales e curvas de níveis, entre outros (v.g. Deffontaines 1989, 1991, Krawczyk \& Zuchiewicz 1989, Zuchiewicz 1991, Golts \& Rosenthal 1993, Rodriguez 1993, Salvador 1994), tendo estas sempre apresentado resultados bastante úteis para o tipo de análise em questão.

Os métodos estruturais tradicionais utilizados para a obtenção de campos de esforços responsáveis pela geração de estruturas tectônicas rúpteis são baseados essencialmente na análise de pares falhas/estrias (v.g.Arthaud 1969, Angelier \& Mechler 1977). Entretanto, nem todos os materiais geológicos se prestam ao registro destas estruturas, principalmente das estrias. Em casos particulares, famílias de juntas que apresentam direções sistemáticas a nível regional vêm se mostrando como ferramentas úteis para a definição dos seus campos de esforços geradores. Estes métodos já foram aplicados por autores como Hancock \& Engelder (1989), Crespo \& Gomez
(1993) e Caputo (1995), entre outros, com sucesso, tendo sido também utilizados neste estudo.

\section{CONSIDERAÇÕES SOBRE A ÁREA DE ESTUDO A}

área em questão situa-se geograficamente entre os paralelos $22^{\circ} 28^{\prime}-22^{\circ} 21^{\prime}$ e $22^{\circ} 43^{\prime}-22^{\circ} 36^{\prime}$ de latitude sul e os meridi-

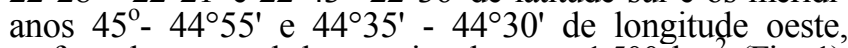
perfazendo um total de aproximadamente $1.500 \mathrm{~km}^{2}$ (Fig. 1). Localizada no macroeixo Rio-São Paulo, abrange porções dos estados do Rio de Janeiro e São Paulo, além de um pequeno trecho de Minas Gerais. As localidades mais importantes da região são Cruzeiro e Queluz (SP), Engenheiro Passos e Itatiaia (RJ), situadas no Vale do Rio Paraíba do Sul. Ao norte encontra-se a Serra da Mantiqueira, onde estão situados os maciços alcalinos de Itatiaia e Passa-Quatro, a oeste ocorre a Bacia de Taubaté e a leste uma pequena porção da Bacia de Resende.
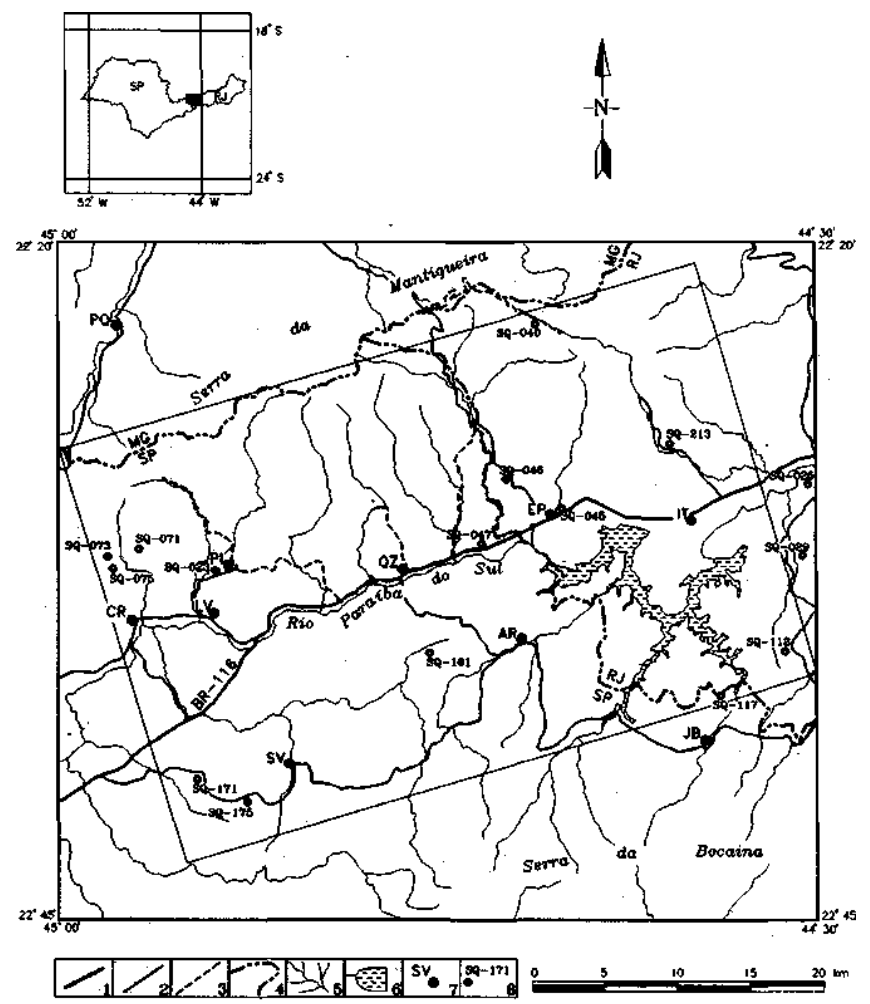

Figura 1 - Localização, principais vias de acesso da área de estudos e afloramentos referidos no texto. 1) auto-estrada; 2) estrada pavimentada; 3) estrada não pavimentada; 4) divisa de estado; 5) drenagens principais; 6) reservatório do Funil; 7) principais localidades: AS- Areias, CR-Cruzeiro, EPEngenheiro Passos, IT- Itatiaia, LV-Lavrinhas, PI- Pinheiros, $P Q$ - Passa Quatro, JB-São José do Barreiro, SV-Silveiras; 8) afloramentos referidos no texto.

Figure 1 - Study area with location of sites raentioned in text. 1) Highway; 2) secondary paved road; 3) secondary unpaved road; 4) Interstate boundary; 5) main drainage; 6) Funil reservoir; 7) main localities: AS- Areias, CR-Cruzeiro, EP- Engenheiro Passos, IT- Itatiaia, LV-Lavrinhas, PIPinheiros, PQ- Passa Quatro, JB- São José do Barreiro, SV- Silveiras; 8) outcrops mentioned in text.

Inserida regionalmente no contexto do Rift Continental do Sudeste do Brasil (Riccomini 1989), feição tectônica anteriormente denominada de Sistema de Rifts da Serra do Mar (Almeida 1976), afloram na área rochas do embasamento pré-cambriano, compostas geralmente por milonito-gnaisses, blastomilonitos, milonitos, gnaisses bandados, gnaisses 
graníticos, xistos, quartzitos, anfibolitos, granitos, pegmatitos, aplitos e migmatitos (Riccomini 1989). São comuns intrusões de diabásio sob a forma de diques e soleiras, correlacionáveis aos derrames da Formação Serra Geral da Bacia do Paraná, que datam do Jurássico Superior ao Cretáceo Inferior (Amaral et al. 1966, Renne et al. 1992, Turner et al 1994). Ocorrem ainda grandes macicos alcalinos e diques associados que datam do-final do Cretáceo ao início do Terciário (Amaral et al 1967, Lauar 1988).

Depósitos sedimentares terciários da Formação Resende (Melo et al. 1985) afloram no extremo oeste e leste da área, preenchendo partes das bacias de Taubaté e Resende, respectivamente. Segundo Riccomini (1989) a Formação Resende é representada por um sistema de leques aluviais associados à planície fluvial de rios entrelaçados, de idade oligocênica, compreendendo rochas rudáceas sustentadas por matriz lamítica e conglomerados com seixos e matacões nas porções proximais dos leques, em associação lateral e interdigitados com lamitos arenosos e níveis conglomeráticos nas porções mais distais. Na planície fluvial predominam arenitos com estratos cruzados em forma de lençol.

Os sedimentos pleistocênicos e holocênicos apresentam distribuição generalizada em toda a área estudada. Foram inicialmente caracterizados em trabalho do IPT (1983), onde foi apresentado um primeiro quadro das relações estratigráficas entre estes depósitos.

Moura \& Meis (1986) elaboraram uma coluna estratigráfica preliminar para depósitos quaternários do Médio Vale do Rio Paraíba do Sul, em especial para a região de Bananal (SP), a qual, segundo os autores, poderia ser estendida para grande parte do Vale do Paraíba. A partir destes estudos, Moura \& Mello (1991) propuseram formalmente uma classificação com base na definição de unidades aloestratigráficas, compreendendo nove aloformações, que representariam depósitos coluviais, colúvio-aluviais e aluviais pleistocênicos eholocênicos.

No que diz respeito às estruturas tectônicas da área, estas podem ser divididas em três grandes grupos: 1) as antigas, do Pré-Cambriano a Eo-Paleozóico, que aluaram como zonas de fraqueza para as reativações posteriores; 2) aquelas relacionadas com a reativação mesozóico-cenozóica da Plataforma Brasileira (Almeida 1967); e 3) as decorrentes da tectônica atuante no Cenozóico (Riccomini 1989).

Riccomini (1989) estabeleceu um quadro de evolução tectônica cenozóica para o Rift Continental do Sudeste do Brasil, compreendendo quatro fases tectônicas distintas:

1) fase extensional NNW-SSE inicial, de idade eocênicaoligocênica, com a formação da depressão original na forma de hemi-graben e o preenchimento vulcano-sedimentar sintectônico (Grupo Taubaté), com a deposição das formações Resende, Tremembé e São Paulo;

2) fase transcorrente sinistrai de direção E-W, com extensão NW-SE e, localmente, compressão NE-SW, provavelmente oligocêniea;

3) fase transcorrente dextral de direção E-W, com compressão NW-SE, pleistocênica superior a holocênica;

4) fase extensional NW(WNW)-SE(ESE), holocênica, afetando depósitos de baixos terraços.

A origem do Alto Estrutural de Queluz estaria relacionada à fase de transcorrência sinistrai, tendo sido o seu soerguimento controlado por esforços transpressivos ao longo de falhas de direções WNW (Riccomini 1989).

Quanto à geomorfologia, o relevo é caracterizado, na porção centro-sul, correspondente ao Vale do Rio Paraíba do Sul, pelo denominado Mar de Morros (e.g. IPT 1982), com morros com topos arredondados e vertentes convexas a retilíneas. $\mathrm{O}$ padrão de drenagem é de alta densidade, dendrítico a retangular, com vales abertos a fechados. Constitui geralmente um conjunto de formas em "meia-laranja". Na porção norte da área, que corresponde à Serra da Mantiqueira, o relevo é representado por escarpas festonadas com topos angulosos e vertentes com perfis retilíneos. A rede de drenagem é de alta densidade com padrão subparalelo a dendrítico e vales fechados.

$\mathrm{Na}$ área, a superficie de aplainamento mais proeminente é a do Japi (Almeida 1964), de idade paleocênica-eocênica, apresentando altitudes muito uniformes, entre 1.200 e 1.300 metros, devido ao soerguimento epirogenético regular e regional, nivelando os mais diversos tipos de rochas. O relevo tipo Apalachiano desta porção do sudeste brasileiro resulta, em sua maior parte, da erosão diferencial desta superfície, que condiciona as altitudes até as quais se elevam as cristas serranas mantidas pelas estruturas mais resistentes (IPT 1982). Distinguem-se ainda duas outras superficies de erosão de grande extensão, correspondendo aos pediplanos $\mathrm{Pdl}$ e $\mathrm{Pd} 2$ (Bigarella \& Andrade 1965). A mais antiga, correlacionável ao pediplano $\mathrm{Pd} 2$, de idade neogênica, nivela os morros cristalinos (IPT 1983). A mais recente nivela as colinas sedimentares e é correlacionável ao pediplano Pdl, do início do Quaternário (Ab'Sáber 1969).

\section{ANÁLISE GEOMORFOLÓGICA E LITOESTRATI-} GRAFICA Geomorfologia A análise geomorfológica foi executada visando a definição das características gerais do relevo, como a morfologia, rupturas de declive, anomalias de drenagem, entre outras, na tentativa de relacioná-las com as estruturas tectônicas presentes e com possíveis estruturas neotectônicas. Para tanto, foram analisados detalhadamente mapas de lineamentos extraídos de imagens de satélite e radar, seguindo o método preconizado por Liu (1987), mapa de gradientes hidráulicos, confeccionado segundo o método proposto por Rodriguez (1993) e mapa de superfícies de bases, elaborado segundo a concepção de Filosofov (1960 apud Jaim 1980).

Os mapas de gradientes hidráulicos e superficies de base foram correlacionados aos mapas de lineamentos, sendo selecionadas as estruturas provavelmente responsáveis pelo controle de algumas das formas das curvas e, conseqüentemente, das formas do relevo, visando a distinção de regiões passíveis de terem sido afetadas por movimentações tectônicas recentes.

Os resultados da análise geomorfológica são objeto de trabalho específico (Salvador \& Riccomini, em preparação), destacando-se:

1) a individualização de dois grandes domínios geomorfológicos principais, com características hidráulicas e de relevo distintas, identificáveis nos dois mapas e altamente correlacionáveis: o domínio norte, com valores elevados tanto para gradientes hidráulicos como para superficies de base, correspondendo à Serra da Mantiqueira, e o domínio sul, com valores baixos de gradientes hidráulicos e superfícies de base, correspondendo ao Vale do Rio Paraíba do Sul;

2) dentro destes domínios foram observadas áreas de gradientes hidráulicos e superficies de base anómalas, com características distintas do conjunto no qual estão inseridas;

3) os valores mais anómalos verificados nos mapas morfométricos estão localizados na área da Barragem do Funil, sendo que outras anomalias de menores valores ocorrem generalizadamente em toda a área, como nas proximidades de Engenheiro Passos, Queluz e Silveiras;

4) as isolinhas de superfícies de base apresentam comportamento mais homogéneo do que aquelas observadas no mapa de gradientes hidráulicos, com valores pouco acima ou abaixo do normal; as formas das curvas, entretanto, mostram nítidas relações com o mapa de lineamentos;

5) nas regiões de Cruzeiro e Itatiaia ocorrem também porções anómalas, agora com baixos valores de gradientes 
hidráulicos e superficies de base, correspondendo às áreas das bacias de Taubaté e Resende;

6) estruturas de direção geral E-W são as prováveis responsáveis pela compartimentação dos dois grandes domínios e, com frequência, mostram nítida sobreposição por outras estruturas mais jovens (Salvador 1994); estas estruturas mais jovens, em especial as de direções NE a NNE e NW aNNW, além das estruturas E-W, são as responsáveis pelo controle das porções anômalas.

A análise dos mapas morfométricos em conjunto com o mapa geológico e a distribuição de sedimentos quaternários, extraída de fotografias aéreas, permitiu a seleção de áreas de maior probabilidade de ocorrência de estruturas neotectônicas e com maior possibilidade de preservação destes registros.

Litoestratigrafia $\mathrm{O}$ estabelecimento da litoestratigrafia dos depósitos sedimentares cenozóicos foi baseada em suas relações estratigráfieas, geomorfológieas e em correlações litológicas com sedimentos descritos na vizinha região de Bananal, cuja coluna aloestratigráfica foi estabelecida por Moura \& Mello (1991)e Mello (1992), e amparadas em idades obtidas pelo método $\mathrm{C}^{14}$

$\mathrm{O}$ reconhecimento de diferentes litotipos e de suas relações geomorfológicas e estratigráfieas permitiu a individualização das seguintes unidades: 1) sedimentos terciários da Formação Resende; 2) depósitos de tálus; 3) depósitos aluviais de antigos terraços do Rio Paraíba do Sul; 4) depósitos coluviais e colúvio-aluviais de primeira geração (pleistocênicos); 5) depósitos coluviais, colúvio-aluviais e aluviais de segunda geração (holoeênicos); e 6) depósitos aluviais de baixos terraços e várzeas atuais (Fig. 2).

SEDIMENTOS TERCIÁRIOS Sedimentos terciários pertencentes à Formação Resende ocorrem a oeste e leste da área de estudos, nas porções correspondentes às bacias de Taubaté e Resende, respectivamente. Estes depósitos têm origem relacionada a um sistema de leques aluviais, distinguindo-se, na região, fácies correspondentes às porções proximais e distais destes leques. Não raramente, os sedimentos da Formação Resende apresentam-se como manchas isoladas, em meio às, rochas do embasamento pré-cambriano do Alto Estrutural de Queluz.

Ao conjunto de sedimentos da Formação Resende foi atribuída idade eocênica-oligocênica, a partir de análises palinológicas executadas na microflora de Resende (Lima \& Amador 1985, Riccomini et al. 1987, Riccomini 1989).

Apesar de não ocorrerem na área abrangida pelo presente estudo, merecem referência os sedimentos da Formação Pindamonhangaba, descritos na porção central da Bacia de Taubaté (Riccomini 1989, Riccomini et al 1991b, Mancini 1995), já que encontram-se inseridos no mesmo contexto geológico e serão referidos por ocasião da caracterização neotectônica. Estes sedimentos representam um sistema fluvial meandrante, de idade neogênica a pleistocênica, separada dos sistemas deposicionais mais antigos por importante discordância basal. Em adição, constituem um depósito de forma tabular, relativamente horizontalizado, caracterizando-se como um verdadeiro datum de referência para os movimentos neotectônicos

SEDIMENTOS PLEISTOCENICOS Dentro das unidades pleistocênicas foram incluídos os depósitos de tálus associados aos maciços alcalinos de Itatiaia e Passa-Quatro, os aluviais de antigos terraços do Rio Paraíba do Sul (além de pacotes de lamitos que, por vezes, os recobrem) e os coluviais e colúvio-aluviais de primeira geração.

Os depósitos de tálus podem ser observados na paisagem como extensas rampas de material rudáceo nas bordas dos maciços alcalinos de Itatiaia e Passa-Quatro, submetidos atu-

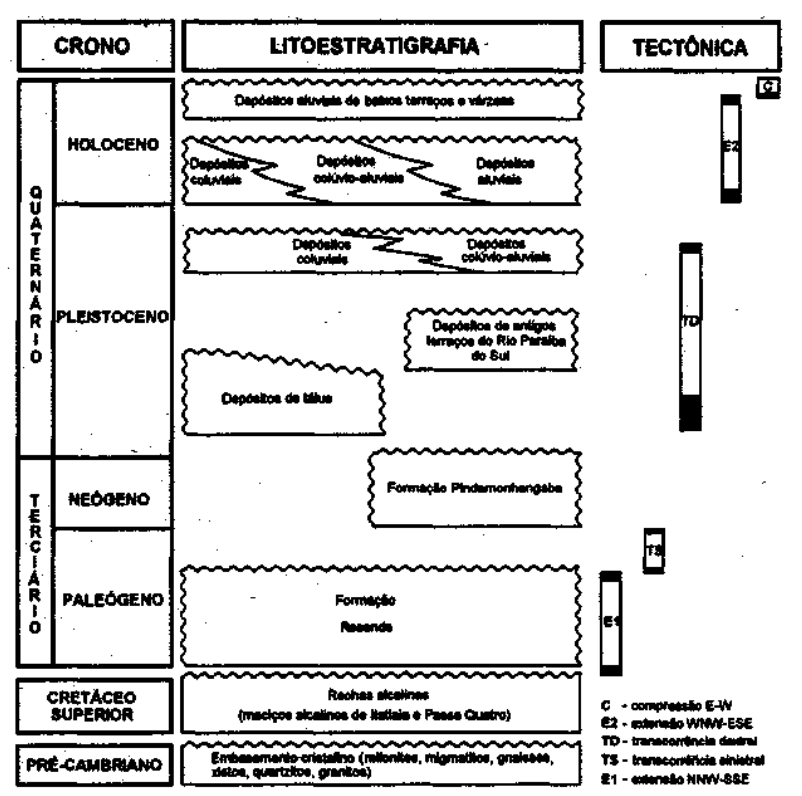

Figura 2 - Coluna litoestratigráfica da região do Médio Vale do Rio Paraíba do Sul compreendida entre Cruzeiro (SP) $e$ Itatiaia $(R J)$.

Figure 2 - Lithostratigraphic column of the study area.

almente a entalhamento pela rede de drenagem; geralmente apresentam contatos erosivos sobre rochas do embasamento, tendo sua origem ligada a movimentos de massa nas bordas dos maciços alcalinos.

Os depósitos aluviais de antigos terracos do Rio Paraíba do Sul estão presentes sempre nas proximidades do atual curso deste rio e, com menor expressão, em alguns de seus afluentes principais; ocorrem localmente na forma de pequenos grabens, tectonicamente embutidos em rochas do embasamento pré-cambriano, com contatos basais erosivos. Nas porções mais arenosas podem ser observados estratos cruzados de baixo ângulo que indicam paleocorrente para leste, coincidente com o sentido atual da drenagem do Rio Paraíba do Sul.

Sobre os depósitos de terraços tem-se localmente pacotes de lamitos cinza-esverdeados, que podem atingir espessuras superiores a $30 \mathrm{~m}$. Apresentam área de ocorrência restrita, estando sua preservação quase sempre ligada a embutimento tectônico, sendo que, em algumas localidades, rochas do embasamento pré-cambriano podem ser observadas cavalgando estes lamitos.

Os depósitos coluviais e colúvio-aluviais de primeira geração encontram-se sobrepostos às rochas do embasamento pré-cambriano, aos sedimentos terciários e aos antigos terraços do Rio Paraíba do Sul, com contatos geralmente erosivos, por vezes tectônicos, ocorrendo generalizadamente em toda a área de estudos, embora de forma descontínua. Os depósitos coluviais estão situados preferencialmente em posições de interflúvios, encostas de morros e cabeceiras de drenagens e os colúvio-aluviais em encostas baixas, sofrendo influências dos processos erosivos atuantes nos vales.

SEDIMENTOS HOLOCENICOS No conjunto dos depósitos holocênicos foram enquadrados os sedimentos coluviais, colúvio-aluviais e aluviais de segunda geração e os sedimentos aluviais atuais de baixos terraços e várzeas.

Depósitos coluviais, colúvio-aluviais e aluvias de segunda geração ocorrem interdigitados e de maneira relativamente contínua em baixas encostas e preenchendo os vales das 
principais drenagens na área de estudos. São distinguíveis na paisagem como rampas suaves que, a partir das encostas, gradam para extensos níveis de terraços colmatando os vales.

Os depósitos eoluviais holocênicos distinguem-se dós pleistocênicos pela sua posição em meias a baixas encostas e pela continuidade comextensos depósitos aluviais. Estes sedimentos guardam relações de contato erosivos e tectônicos com rochas do embasamento e discordâncias erosivas com os depósitos subjacentes.

Determinação radiométrica $\mathrm{C}^{14}$ efetuada em um nível de paleossolo da porção inferior dos depósitos colúvio-aluviais forneceu idade de $10.240 \pm 90$ anos A.P.

Nos sedimentos descritos por Moura \& Mello (1991), também no Médio Vale do Rio Paraíba do Sul, a leste da área em foco, foram observadas as mesmas características litológicas e distribuição espacial, sendo ali desfilados como Aloformação Manso. Níveis de paleo-horizantes $\hat{A}$, localizados próximos à base desta sequência sedimentar, foram datados pelo método $\mathrm{C}^{14}$ e forneceram idades ao redor de 8.500 anos A.P. (Mello et al 1995).

Os sedimentos mais recentes observados compreendem depósitos atuais de baixos terraços e várzeas associados ao Rio Paraíba do Sul e seus afluentes principais, sendo atualmente formados principalmente peia migração dos canais das drenagens e alargamento do leito fluvial. São constituídos por materiais incoesos de barras e fundos de canais nos vales fluviais e sedimentos pelítieos em várzeas.

ANÁLISE NEOTECTÔNICA Os estudos de geologia estrutural na área em foco foram dirigidos no sentido da caracterização das estruturas neotectônieas bem como de seus condicionantes estruturais antigos, visando a identificação e hierarquização de mudanças no campo de esforços durante o Quaternário. Foram cadastrados e analisados mais de um milhar de dados referentes a estruturas tectônicas rúpteis, principalmente juntas, falhas e estrias, em número considerado significativo e representativo.

Os dados foram coletados tanto em sedimentos quaternários como em rochas do embasamento pré-cambriano, rochas dos maciços alcalinos de Itatiaia e Passa-Quatro e sedimentos terciários das bacias de Taubaté e Resende.

Durante as etapas de campo procurou-se estabelecer a cronologia relativa de geração das diferentes estruturas. Os critérios utilizados levaram em conta, principalmente, o deslocamento de uma estrutura por outra, superposição de estrias e formação de degraus em planos de falhas (v.g. Bergerat 1987, Petit 1987, Riccomini 1989). A cronologia das estruturas observadas em sedimentos terciários e quaternários teve também como suporte fundamental a estratigrafia destes depósitos.

Após a coleta, os dados referente às falhas e respectivas estrias de atrito foram tratados em gabinete, seguindo os métodos gráficos de Arthaud (1969) e Angelier \& Mechler (1977).

A aplicação do método de Angelier \& Mechler (1977) visou a obtenção das direções dos eixos principais de encurtamento e extensão, a partir de planos de falhas e estrias, estas últimas representando as tensões cisalhantes sobre os planos de falhas. $\mathrm{O}$ tratamento dos dados segundo o método de Arthaud (1969) visou a definição dos eixos de deformação (X, $\mathrm{Y}$ e $\mathrm{Z}$, sendo $\mathrm{X} \geq \mathrm{Y} \geq \mathrm{Z}$ ) a partir de planos de movimento.

Tendo em vista que nem todos os materiais geológicos se prestam ao registro de estrias, famílias de juntas com direções sistemáticas a nível regional foram utilizadas para a definição de seus campos de esforços geradores, a exemplo de trabalhos executados por Hancock \& Engelder (1989), Crespo \& Gomez (1993) e Caputo (1995). No caso de juntas de extensão o eixo principal mínimo de esforços, $\sigma 3$, orienta-se perpendicularmente ao plano da estrutura. As juntas de cisalhamento ocorrem como famílias conjugadas com esforço principal máximo compressivo, $\sigma 1$, localizado na bissetriz do ângulo agudo destes planos.

O arranjo espacial das estruturas, as movimentações observadas ao longo das falhas, bem como os campos de tensões geradores destas, mostram incompatibilidade com um único evento deformador, necessitando de diferentes regimes de esforços para sua compreensão. Assim, de posse dos estereogramas obtidos, em conjunto com a cronologia relativa das estruturas, observada em algumas localidades descritas, e somado à estratigrafia dos depósitos quaternários, foi possível a distinção de três regimes de esforços específicos, atuantes na região de Cruzeiro-Itatiaia, durante o período considerado neotectônico. Os dois primeiros eventos já haviam sido registrados por Riccomini (1989) e correspondem, inicialmente, a uma fase transcorrente dextral e, posteriormente, a um evento extensional com direção WNW-ESE. No presente estudo foi evidenciado um terceiro registro de caráter compressivo, com direção E-W.

Regime transcorrente dextral $\mathrm{O}$ regime transcorrente dextral está representado principalmente por falhas de direções NW a WNW e ENE, afetando depósitos coluviais e colúvio-aluviais pleistocênicos (Fig. 3). Estas estruturas apresentam movimentações com caráter predominante transcorrente dextral, por vezes com componentes normais. Ao longo de estruturas direcionadas segundo NNW e NNE a NE as movimentações são predominantemente de caráter transcorrente sinistrai, com componentes reversas.

Os planos de falhas e respectivas estrias, analisados por métodos gráficos, forneceram campos de esforços com eixos ai orientados segundo NW-SE, e eixos $\sigma 3$ segundo NE-SW. Dentro do modelo estrutural desenvolvido por Riedel (1929) e anteriormente aplicado na região por Riccomini (1989), as esttuturas de direções NW a WNW e ENE corresponderiam a falhas sintéticas $\mathrm{R}$ e $\mathrm{P}$, respectivamente, e as de direções NNW e NNE a antitéticas R' e X. Estariam, desta forma, sugerindo a vigência de um regime tectônico transcorrente dextral, com binário orientado aproximadamente segundo E-W (Fig. 4).

É possível que parte da formação dos depósitos de tálus seja devida à instabilidade gerada por esta fase neotectônica. Estes sedimentos são também afetados por falhas cujos campos de esforços são compatíveis com binário transcorrente dextral de direção E-W. Na porção central da Bacia de Taubaté estas estruturas seccionam sedimentos da Formação Pindamonhangaba (Riccomini 1989, Mancini \& Riccomini 1994, Mancini 1995).

Ainda relacionadas com a transcorrência dextral, ocorrem falhas de empurrão com superfícies muito irregulares. Tais estruturas são responsáveis pela colocação tectônica de rochas do embasamento sobre sedimentos oligocênicos da Formação Resende e sobre sedimentos lamíticos, provavelmente pleistocênicos, também presentes no topo dos depósitos aluviais mais antigos do Rio Paraíba do Sul (Fig. 5). Estas descontinuidades foram originadas a partir de reativações das extensas estruturas de direção ENE e WNW em zonas transpressionais, com esforço principal máximo compressivo, $\sigma 1$, orientado segundo NW-SE, horizontal, e extensão vertical (Fig. 4B).

A partir das evidências de que as estruturas referentes à fase transcorrente dextral afetam depósitos oligocênicos (Formação Resende), miocênicos-pliocênicos (Formação Pindamonhangaba) e depósitos provavelmente pleistocênicos (coluviais e colúvio-aluviais), não estando impressos nos sedimentos holocênicos, sugere-se para este regime uma idade pleistocênica.

Regime extensional E-W (WNW-ESE) A geração e reativação de estruturas de direções ENE, com movimen- 
tacões sinistrais, por vezes apresentando componentes normais, e de estruturas com direções NNW e movimentações predominantes normais, indicam a vigência de um campo de esforços trativo, orientado segundo a direção geral $\mathrm{E}-\mathrm{W}$ (WNW-ESE), com compressão máxima vertical (Figs. 6 e 7). A reativação das estruturas de direção ENE foi responsável pelo embutimento tectônico de depósitos aluviais mais antigos, relacionados ao Rio Paraíba do Sul, e dos depósitos lamíticos associados, constituindo pequenos grabens de dimensões métricas a decamétricas alojados entre rochas do embasamento. Os sedimentos ficaram protegidos dos processós erosivos posteriores, favorecendo sua preservação (Fig. 8). Adicionalmente, este regime extensional E-W parece ter gerado vales tectônicos de direção N-S, cujos planos de falhas podem ser reconhecidos nas encostas adjacentes pela presença de facetas triangulares; os sedimentos que os preenchem ainda preservam a morfologia deposicional original de leques aluviais (Fig. 9). Estes sedimentos de preenchimento de vales constituem os depósitos coluviais, colúvio-aluviais e aluviais holocênicos, os quais apresentam ampla distribuição em toda a área estudada, colmatando o fundo, dos vales atuais e refletindo um período de intenso entulhamento das drenagens.
O tectonismo extensional relacionado com este regime de esforços, além de provável responsável pela geração dos sedimentos coluviais, colúvio-aluviais e aluviais holocênicos da área estudada, está impresso nestes mesmos sedimentos, atestando seu caráter recorrente. Adicionalmente afeta também os depósitos correlacionáveis da Aloformação Manso. Não raramente ocorrem relações de contatos tectônicos entre os sedimentos e as rochas do embasamento (Fig. 10).

O regime extensional de direção E-W(WNW-ENE) foi provavelmente instalado a partir do início do Holoceno e existem evidências de que tenha perdurado até $270 \pm 120$ anos A.P., idade esta referente aos depósitos de baixos terraços seccionados por falhas normais descritos por Riccomini et al (1991a).

Regime compressivo E-W Um regime tectônico compressivo de direção E-W é representado na área de estudos por uma grande quantidade de famílias de juntas conjugadas e, secundariamente, por algumas falhas de componente reversa.

As juntas ocorrem de maneira generalizada, afetando os depósitos coluviais e colúvio-aluviais pleistocênicos e os

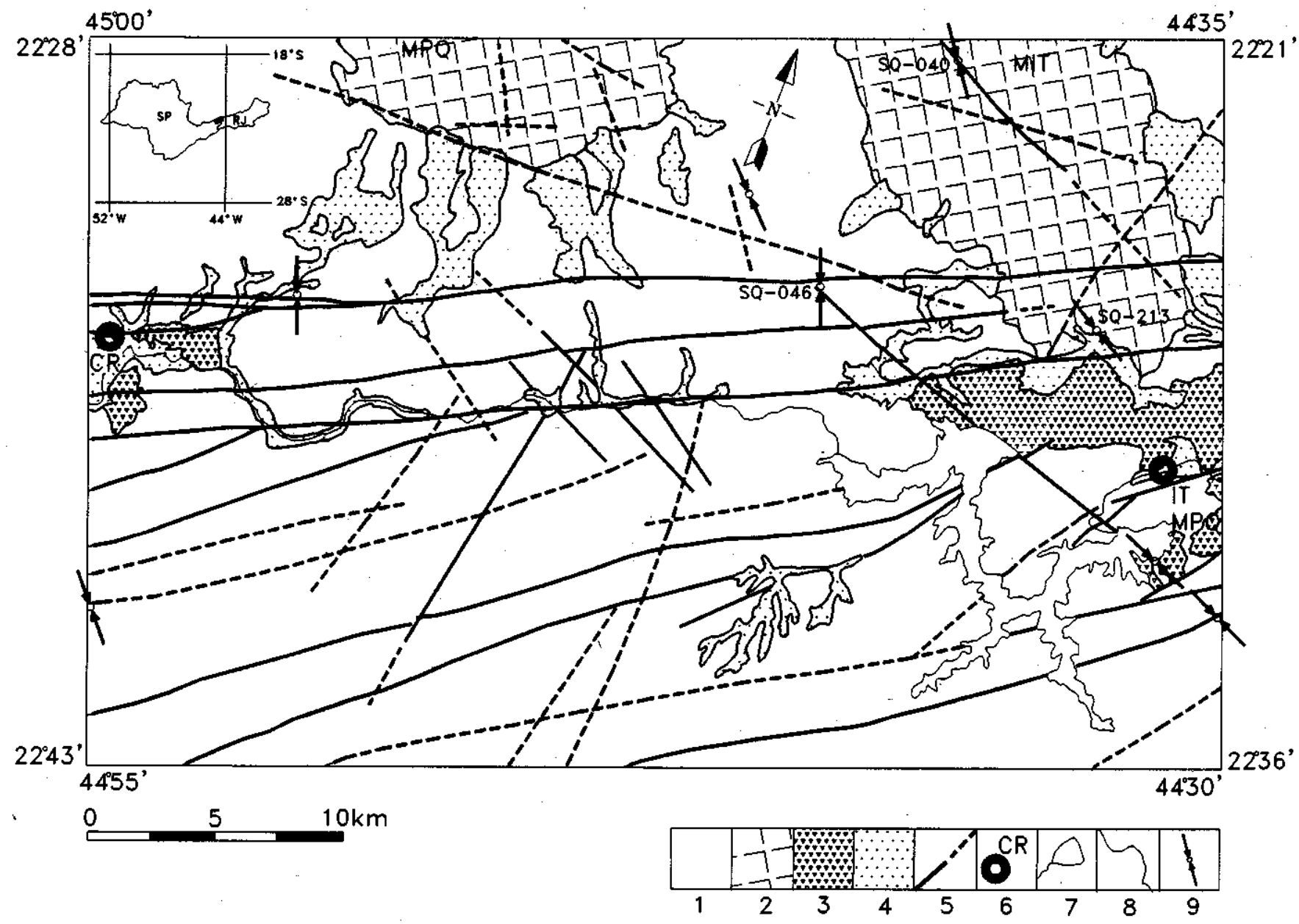

Figura 3 - Direção dos esforços relacionados ao binário transcorrente dextral E-W, com compressão $N W$-SE e extensão $N E-S W$. 1) embasamento pré-cambriano; 2) rochas alcalinas (MPQ-Maciço de Passa-Quatro, MIT-Maciço de Itatiaia); 3) sedimentos da Formação Resende; 4) sedimentos quaternários; 5) falha, falha inferida; 6) direções de esforços compressivos, com respectivas localidades quando referidas na Figura 4; 7) Reservatório do Funil; 8) Rio Paraíba do Sul; 9) principais localidades (IT-Itatiaia, CR-Cruzeiro).

Figure 3 - Direction of stresses related to E-W right-lateral transcurrent binary, with NW-SE compression and NE-SW extension. 1) Precambrian basement rocks; 2) alkaline massifs (MPQ- Passa Quatro, MIT-Itatiaia); 3) sediments of the Resende Formation; 4) Quaternary sediments; 5) fault, inferred fault; 6) direction of compressivo stresses, with locations as shown in Figure 4; 7) Funil reservoir; 8) Paraíba do Sul river; 9) main localities (IT-Itatiaia, CR-Cruzeiro). 


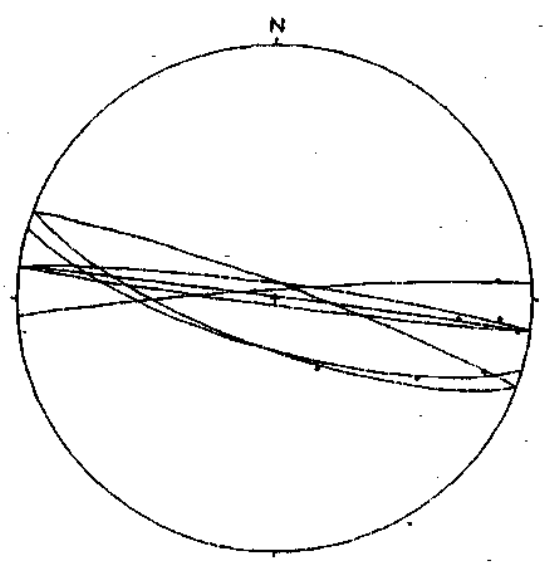

A
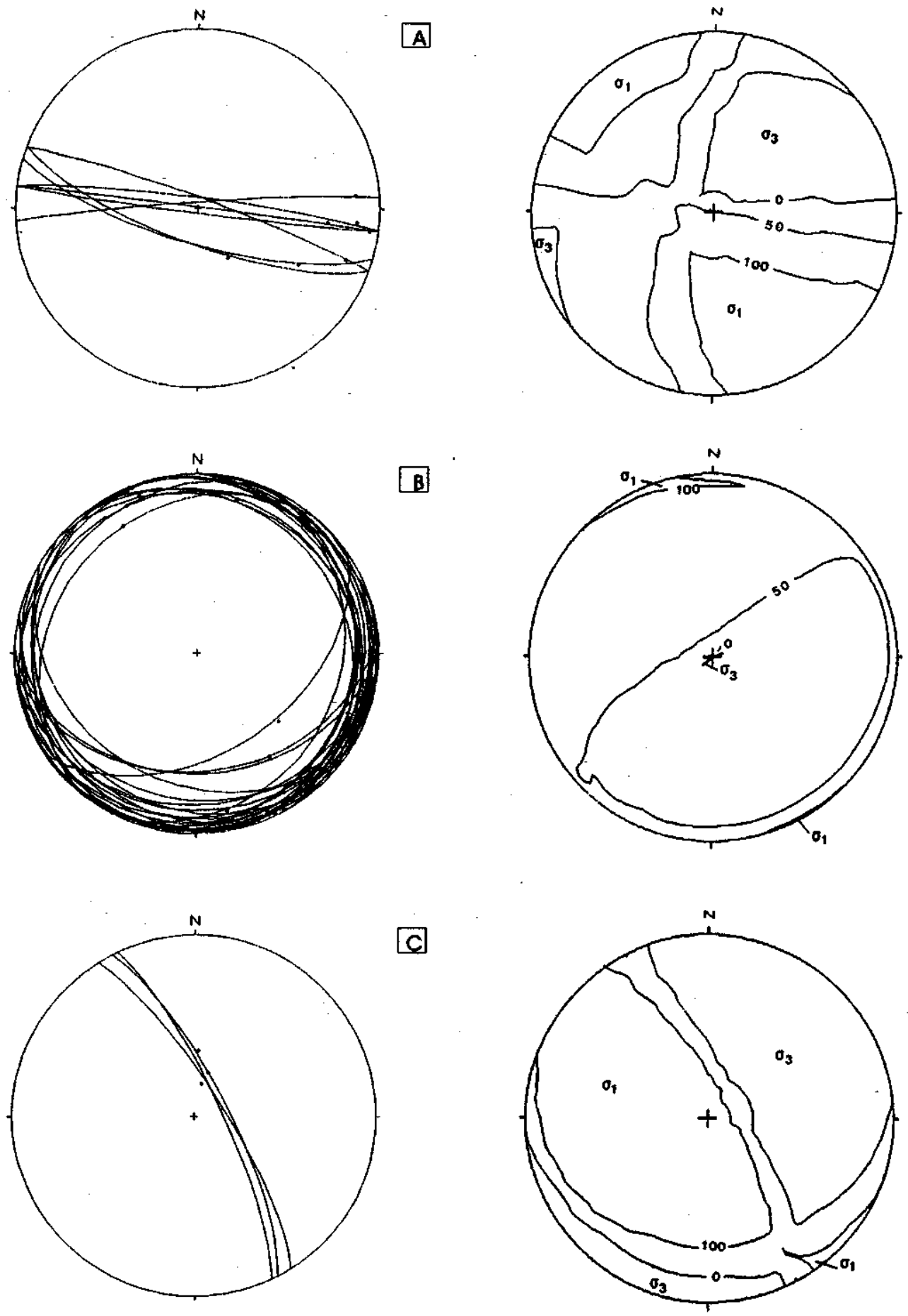

Figura 4 - Exemplos de falhas relacionadas ao binário transcorrente dextral E-W e respectivas direções de esforços geradores: A) falhas de direção WNW e caráter dextral, afetando rochas do Maciço Alcalino de Itatiaia, local SQ-040, 7 dados; B) falhas de empurrão com direçães predominantes $N N W$ a NNE, colocando rochas do embasamento sobre sedimentos da Formação Resende, local SQ-023, 33 dados; C) falhas de direção NNW e caráter normal, afetando depósitos de tálus nas proximidades do Maciço Alcalino de Itatiaia, local SQ-213, 3 dados. A,B,C-lado esquerdo: projeção ciclográfica, diagrama Schmidt-Lambert, hemisfério inferior, onde os círculos máximos representam planos de falhas e os pontos os pólos das estrias; lado direito: dados tratados pelo método gráfico de Angelier \& Mechler (1977), sendo que as isolinhas de porcentagem mais elevada delimitam os campos de maior probabilidade de conter o eixo de tensão máxima, $\sigma 7, e$ as de menor valor o eixo de tensão mínima, $\sigma 3$. Figure 4 - Examples of faults related to the E-W transcurrent binary with directions of generator stress. A) WNW right-lateral stríke-slip faults cutting alkaline rocks of the Itatiaia Massif, site SQ-040, n=7; B) NNW to NNE thrust faults with Precambrian basement rocks over Tertiary sediments of the Resende Formation, site SQ-023, n=33; C) NNW normal faults cutting talus deposits next to the Itatiaia Alkaline Massif, site SQ-213, n=3. A, B, C - equal-area projection, lower hemisphere; on the left: faults (great circles) and striae (dots); on the right: results of application of the method of Angelier \& Mechler (1977) for the faultpopulation, where the higher and lower isoline values (in \%) indicate, respectively, the higher and lower probability field for the maximun $(\sigma 1)$ and minimun $(\sigma 3)$ stress axes. 




Figura 5 - Bloco de gnaisse do embasamento pré-cambriano cavalgado sobre sedimentos lamíticos pleistocênicos. Notar lasca de gnaisse do, embasamento entre os sedimentos na porção central da figura. Estrada das Estâncias (Engenheiro Passos, RJ - Itamonte, MG), local SQ-046. Figure 5 - Block of Precambrian gneissic rocks thrust over Pleistocene mudstones. Note a slice of gneissic rocks within the sediments in the middle part of the outcrop. Site SQ-046, between Engenheiro Passos, RJ, and Itamonte, $\mathrm{MG}$ coluviais, colúvio-aluviais e aluviais holocênicos (Fig. 11). Estas estruturas foram também identificadas nos depósitos da Aloformação Manso.

Caracteristicamente, tais feições ocorrem na forma de juntas de cisalhamento, com famílias conjugadas de direções ENE a NE e WNW a NW, com ângulos que variam de $20^{\circ}$ a $80^{\circ}$, sempre mantendo a bissetriz aguda na direção E-W, de forma bastante persistente (Fig. 12).

Mais raramente, ocorrem juntas de extensão com direções E-W, geralmente verticais e com espaçamento decimétrico a métrico. Por vezes têm-se ainda falhas de direções ENE e NNW, com caráter predominante reverso, geradas a partir da reativação de estruturas mais antigas, em quase todos os casos as mesmas já reativadas na fase anterior.

Famílias conjugadas de juntas de cisalhamento com direções semelhantes às que afetam os depósitos quaternários estão também registradas em rochas do embasamento précambriano. Riccomini (1989) obteve mais de uma centena de medidas destas estruturas em um túnel sob a barragem do Funil, que forneceram eixos compressivos também orientados segundo a direção E-W.

Embora pareça ter havido o controle das antigas estruturas das rochas do embasamento sobre as direções das juntas dos depósitos pleistocênicos e holocênicos, estas relações ainda não foram totalmente elucidadas.

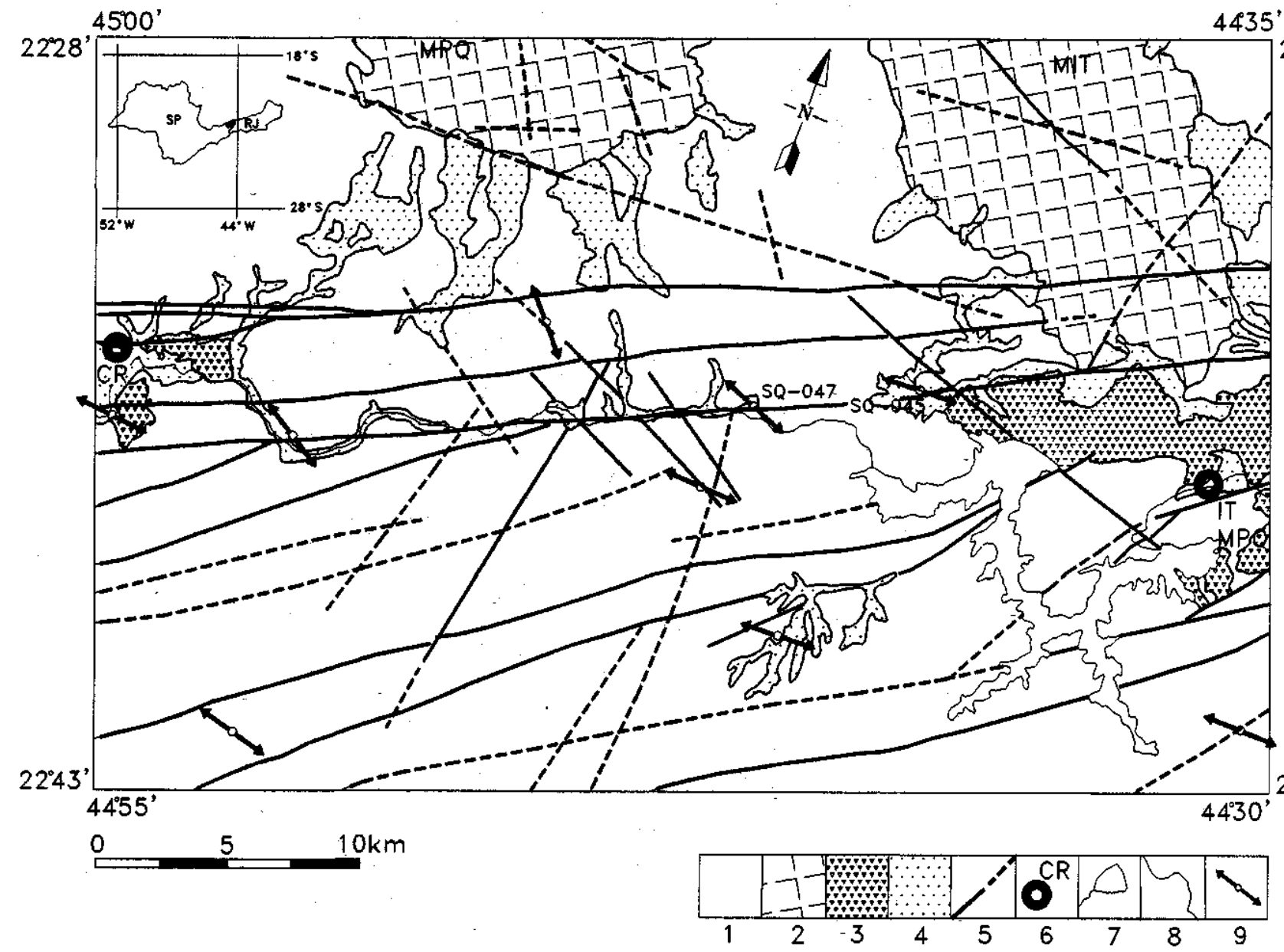

Figura 6 - Direção dos esforços relacionados à extensão de direção E-W (WNW-ESE). 1) embasamento pré-cambriano; 2) rochas alcalinas (MPQ- Maciço de Passa-Quatro, MIT-Maciço de Itatiaia); 3) sedimentos da Formação Resende; 4) sedimentos quaternários; 5) falha, falha inferida; 6) direções de esforços extensionais, com respectivas localidades quando referidas na Figura 7; 7) Reservatório do Funil; 8) Rio Paraíba do Sul; 9) principais localidades (IT-Itatiaia, CR-Cruzeiro).

Figure 6 - Direction of stresses related to E-W (WNW-ESE) extension. 1) Precambrian basement rocks; 2) alkaline massifs (MPQ- Passa Quatro, MIT- Itatiaia); 3) sediments of the Resende Formation; 4) Quaternary sediments; 5) fault, inferred fault; 6) direction of extensional stresses, with locations as shown in Figure 5; 7) Funil reservoir; 8) Paraíba do Sul river; 9) main localities (IT- Itatiaia, CR-Cruzeiro). 

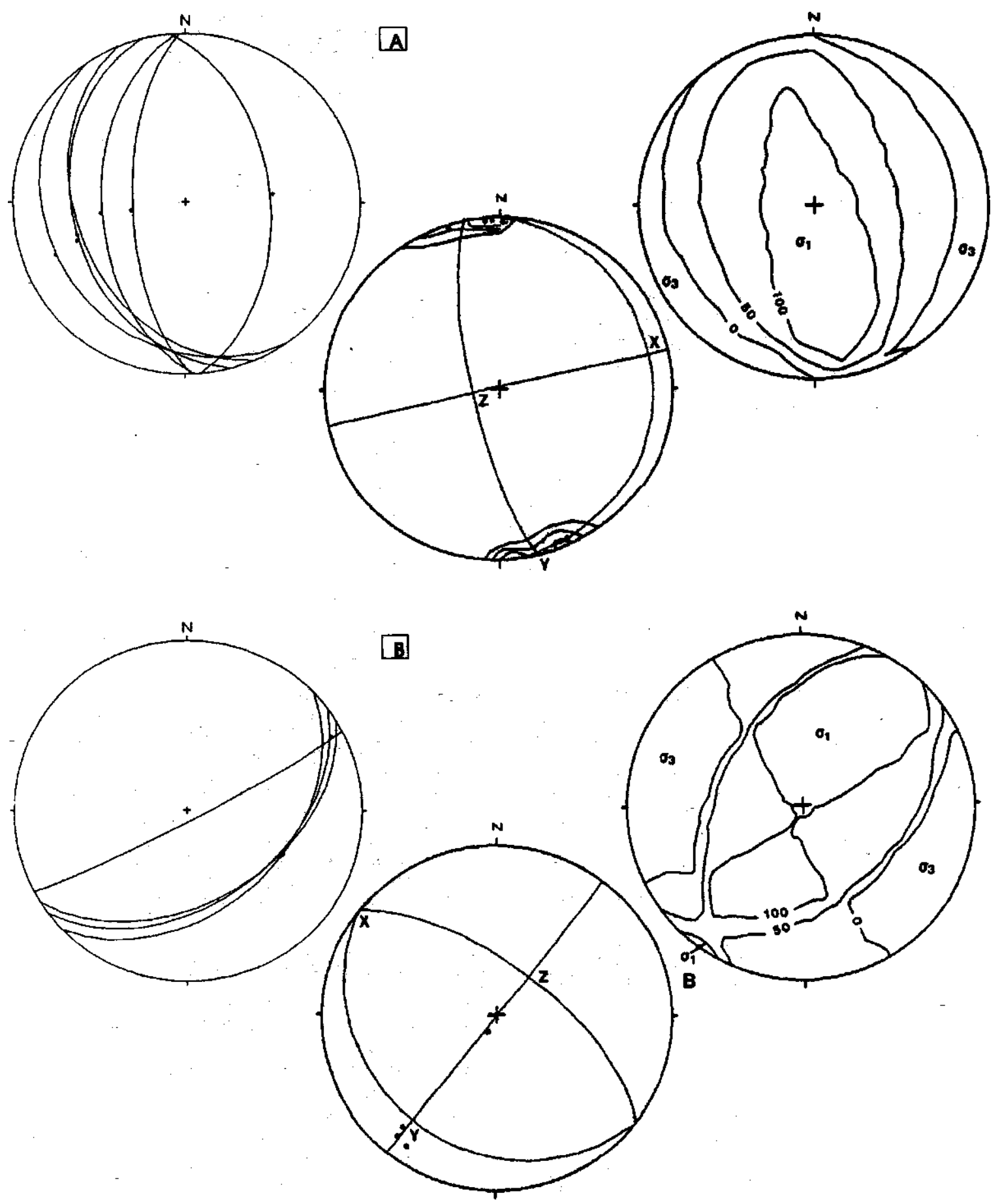

Figura 7 - Exemplos de falhas relacionadas ao regime extensional de direção E-W(WNW-ESE) e respectivas direções de esforços geradores. A) falhas de direção $N N W$ e caráter normal, formadas a partir de extensão $E$ - $W$, constituindo um graben que embute lamitos pleistocênicos entre rochas do embasamento, local SQ-045, 6 dados; B) falhas de direção NE com caráter normal e sinistrai, embutindo sedimentos aluviais de antigos terraços do Rio Paraíba do Sul entre rochas do embasamento, local SQ-047, 4 dados. A, B - lado esquerdo: projeção ciclográfica, diagrama Schmidt-Lambert, hemisfério inferior, onde os círculos máximos representam planos de falhas e os pontos os pólos das estrias; centro: dados tratados pelo método de Arthaud 1969, sendo X, Y $e \mathrm{Z}$, respectivamente, os eixos de extensão, intermediário e de encurtamento; lado direito: dados tratados pelo método gráfico de Angelier \& Mechler (1977), sendo que as isolinhas de porcentagem mais elevada delimitam os campos de maior probabilidade de conter o eixo de tensão máxima, $\sigma 1$, e as de menor valor o eixo de tensão mínima, $\sigma 3$ ).

Figure 7 - Examples of faults related to the E-W (WNW-ESE) extension, with directions ofgenerator stress. A) NNW normal faults delimiting a graben filled with Pleistocene sediments within Precambrian basement rocks, site SQ-045, n=6; B) NE normal and left-lateral faults of the borders of a small graben-like feature filled with Pleistocene sediments within Precambrian basement rocks, site SQ-047, n=4. A, B - equal-area projection, lower hemisphere; on the left: faults (great circles) and striae (dots); center: results of application of the method of Arthaud (1969), where X,Y and Z are, respectively, the extension, intermediate and compression axes; on the right side: results of application of the method of Angelier \& Mechler (1977) where the higher and lower isoline values (in \%) indicate, respectively, the higher and lower probability field for the maximun $(\sigma 1)$ and minimun $(\sigma 3)$ stress axes. 


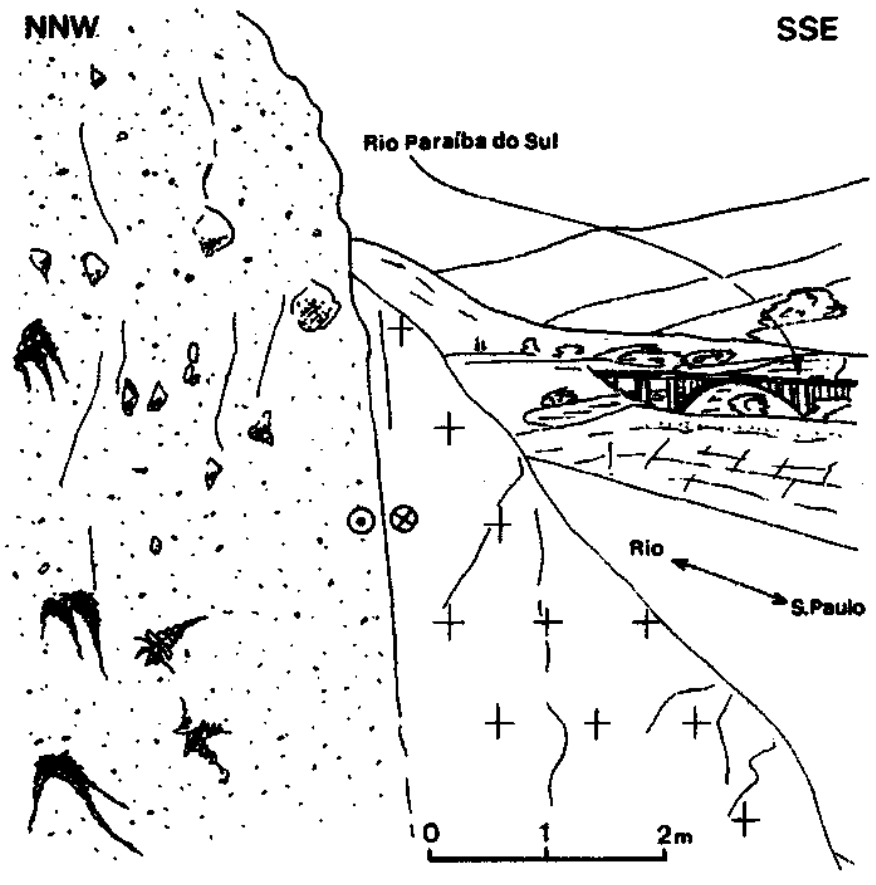

Figura 8 - Sedimentos aluviais de antigos terraços do Rio Paraiba do Sul, (conglomerados com seixos a blocos arredondados de rochas gnáissicas, granitóides, alcalinas e quartzíticas, sustentados por matriz arenosa conglomerática), situados no lado esquerdo da figura, embutidos tectonicamente em rochas gnáissicas do embasamento pré-cambriano, situados na parte direita da figura. O contato é feito por falhamento transcorrente sinistrai. Corte na Rodovia BR-116 (Rodovia Presidente Dutra), próximo à divisa interestadual $S P / R J$, local SQ-047.

Figure 8 - Pleistocene alluvial terraces of the Paraiba do Sul river (on the left) in contact with Precambrian gneissic rocks (on the right) along a left-lateral transcurrent fault. Site SQ-047, Presidente Dutra Highway (BR-116), near the state boundary between São Paulo and Rio de Janeiro.

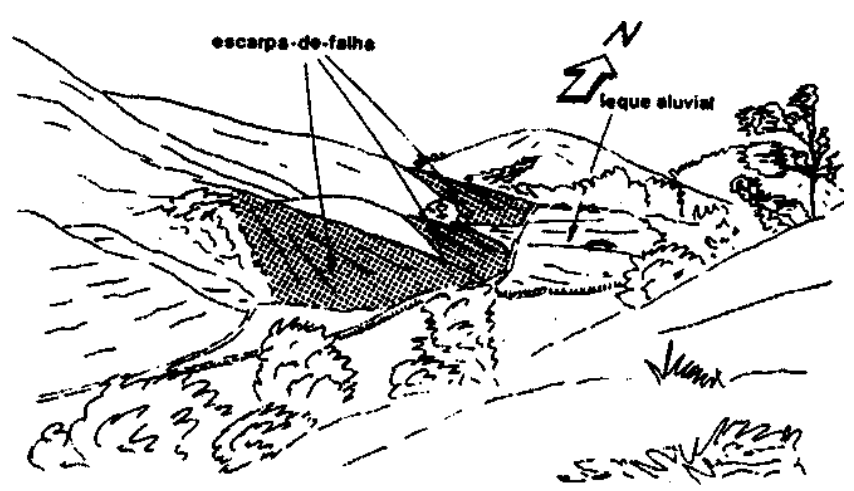

Figura 9 - Vale de direção N-S com feição de escarpa-de-falha (facetas triangulares) e morfologia de leques aluviais ainda preservados, ao sul da Cidade de Resende, local SQ-029.

Figure 9 - N-S-trending valley with well-preserved fault-scarp features (triangular facets) and alluvial fan, south of Resende, site SQ-029.

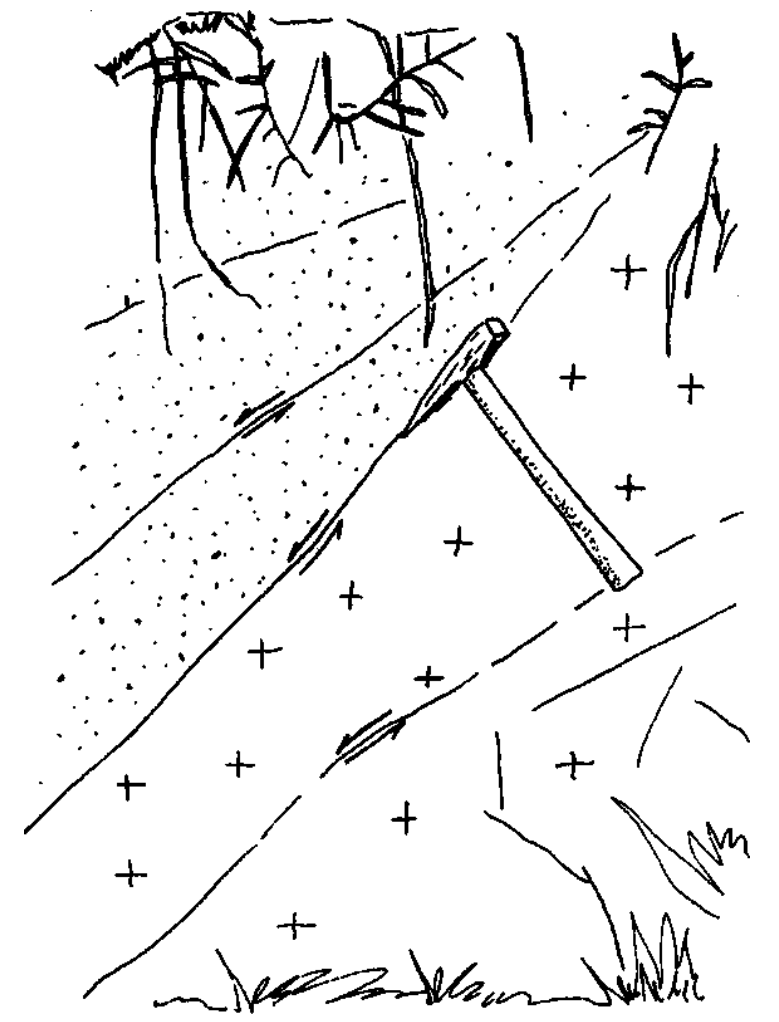

Figura 10 - Sedimentos coluviais da Aloformação Manso, de idade holocênica (porção superior esquerda da figura), em contato por falha normal com rochas do embasamento (porção inferior direita da figura). Estrada Rialto-Bananal, a 4,8 km a sudoeste de Rialto, fora dos limites do mapa da Figura 1.

Figure 10 - Holocene colluvial deposits of the Manso Aloformation (upper left), in contact along a normal fault with Precambrian basement rocks (lower right). Unpaved road between the towns of Rialto and Bananal, $4.8 \mathrm{~km}$ southwest of Rialto, outside the limits of Figure 1.

CONSIDERAÇÕES FINAIS Os mapas morfométricos, correlacionados ao mapa de lineamentos e ao mapa geológico, foram de grande utilidade para a localização de evidências diretas de atividade tectônica recente, visto que as áreas anómalas e suas prováveis estruturas controladoras foram, frequentemente, relacionadas a falhas neotectônicas, impressas nas rochas e nos sedimentos do Alto Estrutural de Queluz.

Os dados obtidos em campo e tratados graficamente, visando a obtenção dos campos de esforços responsáveis pela geração ou reativação das estruturas, permitiram a elaboração de um quadro neotectônico para a região, contemplando três regimes distintos.

Dentro deste quadro, no final do Neógeno ou início do Pleistoceno teriam sido depositados, os sedimentos aluviais mais antigos, relacionados ao Rio Paraíba do Sul. Os depósitos lamíticos, que localmente os recobrem, indicariam o início de um evento tectônico que teria propiciado a desestabilização do relevo. Parte dos depósitos de tálus, presentes nas bordas dos maciços alcalinos de Itatiaia e Passa-Quatro, parecem estar relacionados também a esta fase de instabilidade.

Depósitos coluviais e colúvio-aluviais pleistocênicos, hoje observados em posições de interflúvios, são também afetados por este tectonismo, de caráter transcorrente, relacionado a um binário dextral de direção aproximada $\mathrm{E}-\mathrm{W}$, que teria sido ativo durante o Pleistoceno. O campo de esforcos deduzido indica compressão de direção NW-SE e extensão NE-SW, 
correspondendo às primeiras movimentações neotectônicas registradas através das estruturas rúpteis da área.

Durante o Holoceno teria ocorrido nova mudança no campo de esforcos caracterizando um regime extensional de direção E-W (WNW-ESE). As estruturas então geradas afetaram os sedimentos aluviais antigos do Rio Paraíba do Sul, bem como os lamitos e os depósitos coluviais e colúvio-aluviais pleistocênicos. Estes esforços originaram também vales tectônicos de direção N-S, acarretando novo período de instabilidade da paisagem, com retomada dos processos erosivos e fornecimento de sedimentos coluviais, colúvio-aluviais e aluviais holocênicos. São depósitos relativamente extensos e espessos que entulham os vales das principais drenagens da região. Adicionalmente, esta fase neotectônica encontra-se também impressa nestes sedimentos de preenchimento de vales, o que faz supor que tenha sido iniciada por volta de $10.240 \pm 90$ anos A.P. e perdurando, no mínimo, até $270 \pm$ 120 anos A.P.

Outra mudança no campo de esforços é indicada pelas famílias de juntas conjugadas de direções ENE e WNW, que apontam para uma nova etapa de atividade neotectônica, agora de caráter compressivo, com direção E-W. Este regime teria sido instalado provavelmente após o extensional E-W e perdurado até o presente.

Dados apresentados no 'Mapa Mundial de Esforços' (World Stress Map) obtidos através de análises de breakouts de furos de sondagens, mecanismos focais de terremotos, falhas geológicas e medidas in-situ, indicam a vigência atual de um campo de esforços compressivos, de direção E-W, principalmente na porção oeste da América do Sul, perdurando desde o Pleistoceno Inferior, com provável diminuição da compressão no Pleistoceno Médio. Em direcão a leste estes esforços apresentam variações, sofrendo influências de outros fatores locais, como por exemplo diferenças de espessura crustal, carga de sedimentos em bacias vizinhas e proximidades à margem continental (Assumpção 1992, Mercier et al. 1992, Lima \& Nascimento 1994).

O que pode ser deduzido a partir dos dados obtidos para a região da Soleira de Queluz são mudanças relativamente rápidas dos esforços durante o período neotectônico, quando comparadas às que ocorrem na região andina. Esta última, por estar localizada próxima à margem tectonicamente ativa, registra de forma mais intensa os efeitos da interação compressiva entre as placas de Nazca e Sul-Americana. Na regiấo

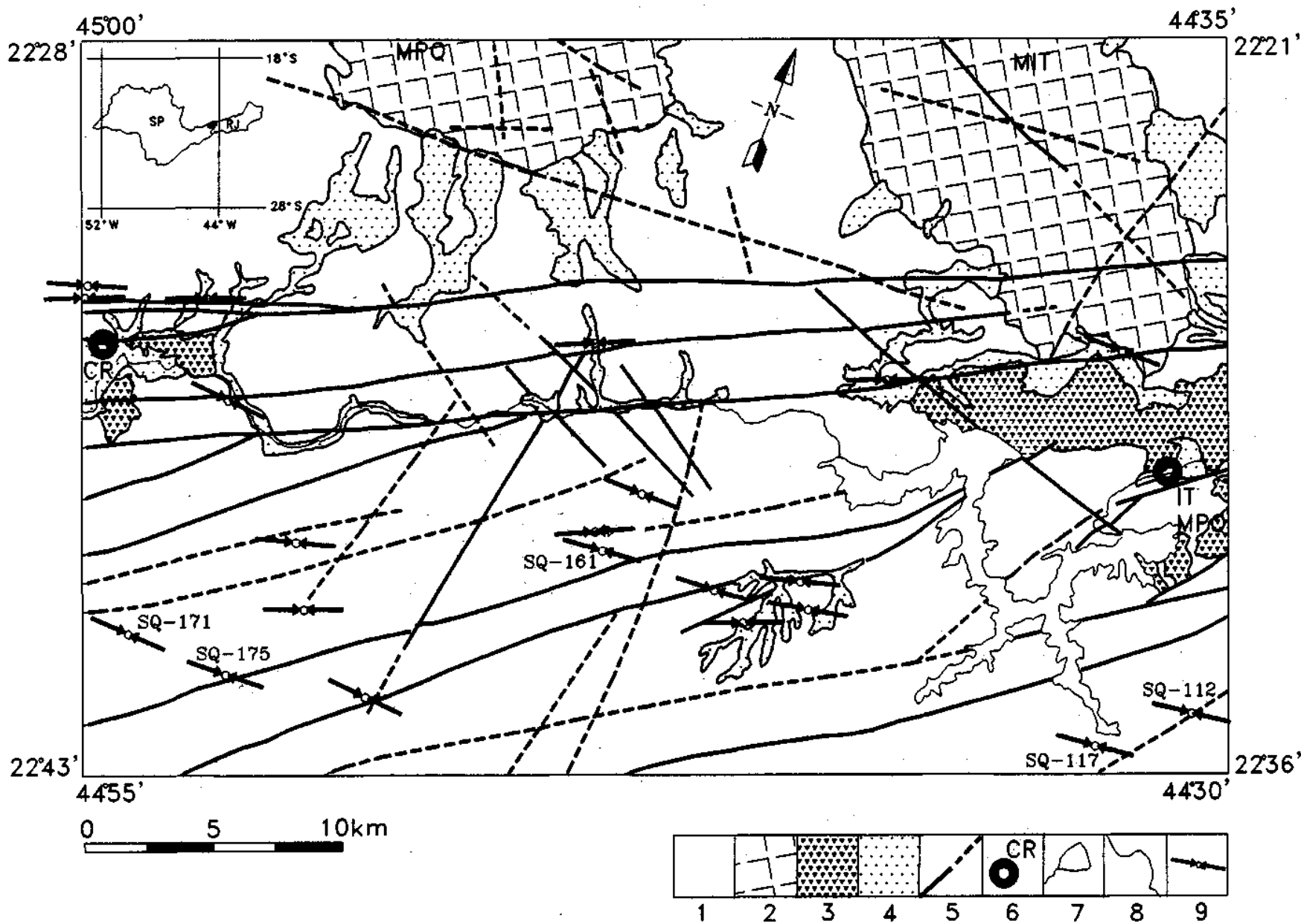

Figura 11 - Direção dos esforços relacionados à compressão final de direção E-W. 1) embasamento pré-cambriano; 2) rochas alcalinas (MPQ- Maciço de Passa-Quatro, MIT- Maciço de Itatiaia); 3) sedimentos da Formação Resende; 4) sedimentos quaternários; 5) falha, falha inferida; 6) direções de esforços compressivos, com respectivas localidades quando referidos na Figura 12; 7) Reservatório do Funil; 8) Rio Paraíba do Sul; 9) principais localidades (IT-Itatiaia, CR- Cruzeiro).

Figure 11 - Directions of stresses related to the final E-W compression. 1) Precambrian basement rocks; 2) alkaline massifs (MPQ- Passa Quatro, MIT- Itatiaia); 3) sediments of the Resende Formation; 4) Quaternary sediments; 5) fault, inferred fault; 6) direction of compressivo stresses, with locations as shown in Figure 12; 7) Funil reservoir; 8) Paraíba do Sul river; 9) main localities (IT- Itatiaia, CR-Cruzeiro). 


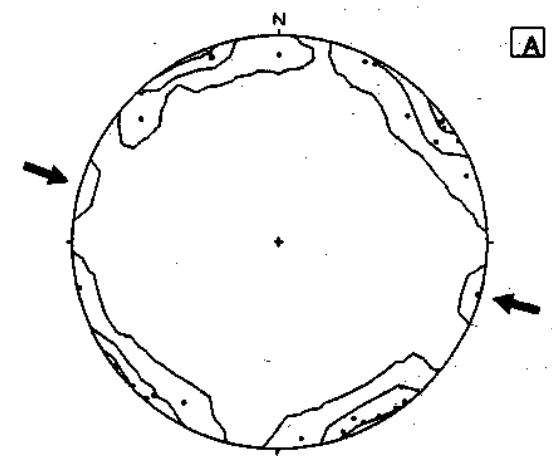

I.C. $=1,6,12 \%$

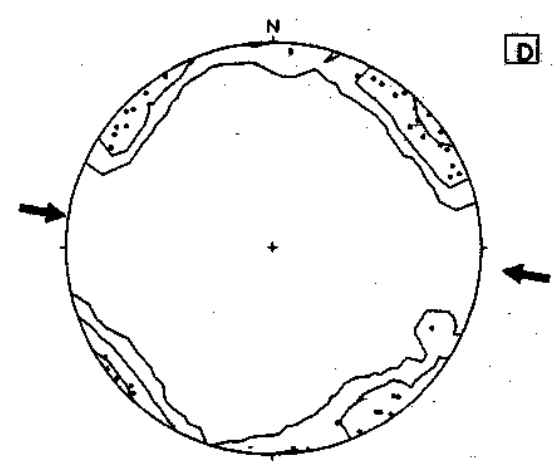

I.C. $=1,4,12 \%$

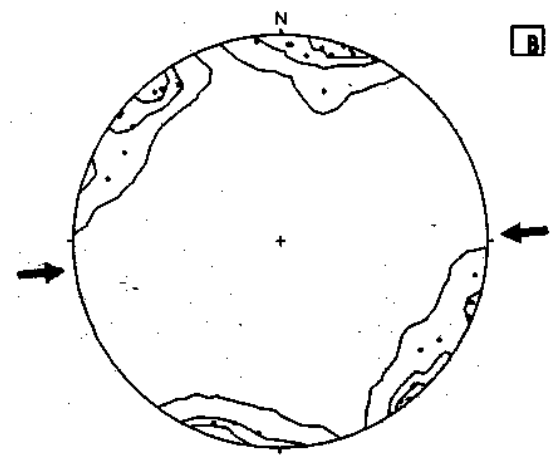

$1 . C_{n}=1,6,9 \%$

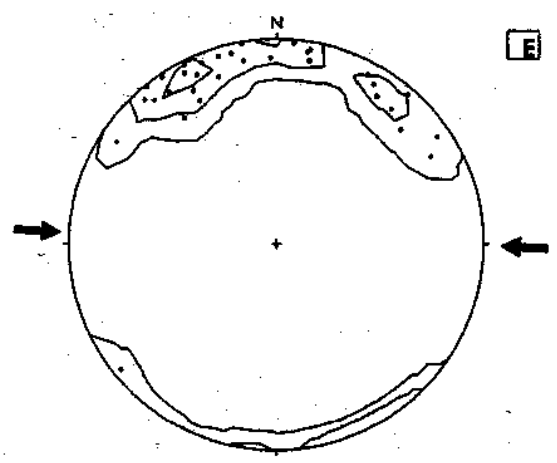

l.C. $=1,5,12 \%$



LC. $=1,5,15 \%$

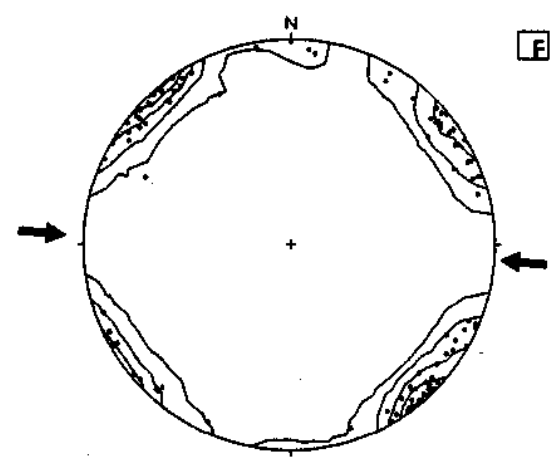

t.C. $=1,4,8,12,16 \%$

Figura 12 - Exemplos de juntas relacionadas à compressão de direção geral E-W e respectivas direções de esforços geradores. A) pólos de planos de juntas conjugadas afetando depósitos coluviais de segunda geração, local SQ-025 (vide localização no mapa da Figura 1), 30 dadçs; B) pólos de planos de juntas conjugadas afetando depósitos coluviais de primeira geração, locais SQ-071, SQ-073 e SQ-O75,34 dados; C) poios de planos de juntas conjugadas afetando depósitos coluviais de primeira e segunda gerações, locais SQ-112 e SQ-117, 29 dados; D) pólos de planos de juntas conjugadas afetando depósitos colvviais de segunda geração, local SQ-161, 43 dados; E) pólos de planos de juntas conjugadas afetando depósitos coluviais de primeira e segunda gerações, locais SQ-171 e SQ-175, 34 fados; F) pólos de planos de juntas conjugadas afetando depósitos coluviais da Aloformação Manso (estrada Bananal-Rialto, a 1, $7 \mathrm{~km}$ a nordeste de Bananal, fora dos limites do mapa da Figura 1), 100 dados. Todos os estereogramas foram confeccionados em diagrama Schmidt-Lambert, hemisfério inferior de referência; I. C. = intervalos de contorno das isolinhas,

a partir do centro; as setas indicam a direção dos eixos de encurtamento ( $\sigma 1)$.

Figure 12 - Examples of fatnilies of joints related to the E-W compression, with the directions of generator stress. A) Holocene colluvial deposits, site SQ-025 (see Figure 1 for location), n=30; B) Pleistocene colluvial deposits, sites SQ-071, SQ-073 and SQ-075, n=34; C) Pleistocene and Holocene colluvial deposits, sites SQ-112 and SQ-117, n=29; D) Holocene colluvial deposits, site SQ-161, $n=43$; E) Pleistocene and Holocene colluvial deposits, sites SQ-171 e SQ-175, n=34; F) colluvial deposits of the Manso Aloformation (unpaved road between the towns of Bananal and Rialto, $1.7 \mathrm{~km}$ northeast of Bananal, outside the limits of Figure 1), $\mathrm{n}=100$. Equal-area projection, lower hèmisphere; I.C.= contour interval of isolines, from the centerof the diagram; arrows indicate the shortening direction $(\sigma 1)$.

estudada, fatores locais devem ser levados em consideração na interpretação das possíveis forças motoras responsáveis pêlos esforços observados na crosta, como por exemplo a proximidade com a margem continental e a carga de sedimentos acumulados nesta, bem como a proximidade com as serras da Mantiqueira e da Bocaina. Além dos esforços se refletirem de modo diferente, já que são relativamente menos intensos do que nas zonas ativas, são também controlados por descontinuidades preexistentes que vêm sendo reativadas desde as fases iniciais de abertura do Oceano Attântico.

As alternâncias de regimes de esforços constatados podem significar um estágio de relaxamento, representado pela extensão E-W, dentro de um regime tectônico compressivo, assinalado pelas fases compressivas NW-SE (transcorrência dextral) e E-W. Uma hipótese altamente especulativa para este relaxamento poderia ser aventada se considerada a sobregarga na área oceânica derivada da enorme quantidade de água de degelo após a última glaciação - pós 17.000 A.P. -promovendo esforços trativos nas regiões próximas à margem continental. Em termos de estabilidade geológica regional e suas implicações para a atividade humana, os dados apresentados demonstraram claramente a necessidade de serem executados levantamentos mais detalhados na área das grandes obras, já que, no âmbito da região do Vale do Rio Paraíba do Sul compreendida entre Cruzeiro (SP) e Itatiaia (RJ), a existência de movimentos neotectônicos recorrentes parece estar suficientemente comprovada.

Agradecimentos Os autores agradecem o apoio financeiro e científico proporcionado pela FAPESP (processos $n^{\circ}$ 93/0633-8 e 92/4020-8) e CNPq (processo n ${ }^{\circ} 303910 /$ 
86-0). Agradecem também aos colegas Fernando Mancini, Liliana S. Osako, Cláudio L. Mello e Lucy G. Sant'Anna pela participação em parte dos trabalhos de campo, e aos Profs.
Drs. Kenitiro Suguio, Marcelo S. Assumpção, Armando M. Coimbra e Ginaldo A. C. Campanha pelas críticas e sugestões apresentadas.

\section{REFERÊNCIAS}

AB'SÁBER, A.N. (1969) O Quaternário na Bacia de Taubaté: estado atual dos conhecimentos. Geomorfologia, 7:22p.

ALMEIDA, F.F.M. de (1964) Fundamentos geológicos do relevo paulista. Boi IGG, 41:169-263.

ALMEIDA, F.F.M. de (1967) Origem e evolução da Plataforma Brasileira. Rio de Janeiro, DNPM/DGM, 36p. (Boletim 241)

ALMEIDA, F.F.M. de (1976) The system of continental rifts bordering the Santos Basin, Brazil. An. Acad. bras. CL, 48:15-26.

AMARAL, G.; CORDANI, U.G.; KAWASHITA, K.-; REYNOLDS, J.H. (1966) Potassium-Argon dates of basaltic rocks from Southern Brazil. Geoch. Cosmoch. Acta, 30:159-189.

AMARAL, G.; BUSHEE, J.; CORDANI, U.G.; KAWASHITA, K.; REYNOLDS, J.H. (1967) Potassium-argon ages of alkaline rocks from Southern Brazil. Geoch. Cosmoch. Acta, 31:117-142.

ANGELIER, J. \& MECHLER, P. (1977) Sur une méthode graphique de recherche dês contraintes principales également utilisable en tectonique et en séismologie: Ia méthode dês dièdres droits. Bull. Soe. Géol France, 7:1309-1318.

ARTHAUD, F. (1969) Méthode de déterminatioft graphique dês directions de raccourcissement, d'allongement et intermédiaire d'une population de failles. Bull. Soe. Géol. France, 11:729-737.

ASSUMPÇÃO, M. (1992) The regional intraplate stress field in South America. J. Geophys. Rés.,97:11889-11903.

BERGERAT, F. (1987) Stress fields in the European Platform at the time of Africa-Eurasia collision. Tectonics, 6:99-132.

BIGARELLA, J.J.\& ANDRADE, G.O. (1965) Contribution to the study of the brazilian quaternary. In: GEOLOGICAL SOCIETY OF AMERICA. International studies on the quaternary. S.1.P. p.333-451. (Special paper 84).

CAPUTO, R. (1995) Evolution of orthogonal sets of coeval extension joints. Terra Nova, 7:479-490.

CRESPO, L.E.A. \& GOMEZ, J.L.S. (1993) El sistema de diaclasas N-S en el sector central de Ia Cuenca dei Ebrõ. Relación com el campo de esfuerzos neógeno. Rev. Soe. Geol. Espana, 6:115-122.

DEFFONTAINES, B. (1989) Proposition of a morpho-neotectonic method application in the Forgères área, Oriental Britany, France. Bull. INQUA Neotectonics Commission, 12:48-52.

DEFFONTAINES, B. (1991) Contribution of drainage network analysis to neotectonic: method and application in France. Bull. INQUA Neotectonics Commission, 14:16-17.

FREITAS, R.O. (1956) Considerações sobre a tectônica e a geologia do Vale do Paraíba. Eng. Min. Met., 24:276-283.

GOLTS, S. \& ROSENTHAL, E. (1993) A morphotectoníc map of the northern Arava in Israel, derived from isobase lines. Geomorphology, 7:305-315.

HANCOCK, P.L. \& ENGELDER, T. (1989) Neotectonic joints. Geol. Soe Am. Bull, 101:1197-1208.

HASUI, Y. (1990) Neotectônica e aspectos fundamentais da tectônica ressurgente no Brasil. In: WORKSHOP SOBRE NEOTECTÔNICA E SEDIMENTAÇÃO CENOZÓICA CONTINENTAL NO SUDESTE BRASILEIRO, 1, Belo Horizonte. Boletim SBG/MG, 11:1-31.

INSTITUTO DE PESQUISAS TECNOLOGICAS DO ESTADO DE SÃO PAULO S/A - IPT (1982) Geologia, tectônica, geomorfologia e sismologia regionais de interesse às usinas nucleares da praia de Itaorna. IPT, São Paulo, 149p. (Monografia 7).

INSTITUTO DE PESQUISAS TECNOLÓGICAS DO ESTADO DE SÃO PAULO S/A - IPT (1983) Estudos geológico-tectônicos na Bacia de Resende (RJ) e sedimentos terciários de Volta Redonda (RJ) e Bacia de Taubaté (área de Cruzeiro-SP). Relatório 17.737, IPT, São Paulo, $124 \mathrm{p}$.

JAIM, V.E. (1980) Geotectónicageneral. Mir, Moscou, v.1, 356p.

KRAWCZYK, A. \& ZUCHIEWICZ, W. (1989) Drainage basin parameters within neotectonically active áreas: the Northern Carpathian example. Bull. INOUA Neotectonics Commission, 12:46-47.

LAUAR, C.R.M. (1988) Estudo paleomagnético dos maciços alcalinos de Poços de Caldas, Passa Quatro e Itatiaia. São Paulo, 101 p. (Dissertação de mestrado apresentada ao Instituto Astronómico e Geofísico da Universidade de São Paulo).

LIMA, C.C. \& NASCIMENTO, E.M. (1994) Determinação das direções de tensão máxima horizontal (Shmax) nas bacias sedimentares brasileiras através das análises de "breakouts".Rio de Janeiro, PETROBRÁS, Rio de Janeiro, 23 p. (Comunicação técnica SETEC 007/94).
LIMA, M.R. \& AMADOR, E.S. (1985) Análise palinológica de sedimentos da Formação Resende, Terciário do Estado do Rio de Janeiro, Brasil. Coletânea de trabalhos paleontológicos, Série Geologia, Seção Paleontologia e Estratigrafia, DNPM, 27:371-378.

LIU, C.C. (1987) A geologia estrutural do Estado do Rio de Janeiro vista através de Imagens MSS do LANDSAT. In: SIMPOSIO DE GEOLOGIA, RJ-ES, 1, Rio de Janeiro. Anais. Rio de Janeiro, SBG, p.164-188.

MANCINI, F. (1995) Estratigrafia e aspectos da tectônica defarmadora da Formação Pindamonhangaba, Bacia de Taubaté, SP. São Paulo, 107p. (Dissertação de mestrado apresentada ao Instituto de Geociências da Universidade de São Paulo).

MANCINI, F. \& RICCOMINI, C. (1994) Estilos estruturais da Formação Pindamonhangaba, Bacia de Taubaté, SP. In: CONGRESSO BRASILEIRO DE GEOLOGIA, 38, Camboriú. Boletim de resumos expandidos. Gamboriú, SBG, v.l, p.564-565.

MELLO, C.L. (1992) Fácies sedimentares, arquitetura deposicional e relaçóes morfoestratigráficas em um sistema de leques aluviais holocênicos: Aloformação Manso - Médio Vale do Rio Paraíba do Sul $(S P / R J)$. Rio de Janeiro, 188 p. (Dissertação de mestrado apresentada ao Centro de Ciências Matemáticas e da Natureza da Universidade Federal do Rio de Janeiro).

MELLO, C.L.; MOURA, J.R.S.; CARMO, I.O.; SILVA, T.M.; PEIXOTO, M.N.O. (1995) Eventos de sedimentacão durante o Holoceno no Médio Vale do Rio Paraíba do Sul (SP/RJ) -aloestratigrafia e datacões por radiocarbono. In: CONGRESSO DA ASSOCIAÇÃO BRASILEIRA DE ESTUDOS DO QUATERNÁRIO, 5, Niterói. Anais. Niterói, ABEQUA, p.193-200.

MELO, M.S.; RICCOMINI, C.; ALMEIDA, F.F.M.; HASUI, Y. (1985) Sedimentação e tectônica da Bacia de Resende - RJ. An. Acad. bras. Ciênc. 57:467=479.

MERCIER, J.L.; SEBRIER, M.; LAVENU, A.; CABRERA, J.; BELLEER, O. DUMONT, J.F.; MACHARE, J. (1992) Changes in the tectonic regime above a subduction zone on Andean type: the Andes of Peru and Bolia during the Pliocene-Pleistocene. J. Geophys. Rés., 97:11945-11982.

MÖRNER, N.A., ed (1989) Paleoseismicity and neotectonics. Bull. INQUA Neotectonics Commission, 12:104p.

MÖRNER, N. A. (1993) Neotectonics, the new global tectonic regime during the last $3 \mathrm{Ma}$ and the initiation of Ice Ages. An. Acad. bras. CL, 65:295-301.

MOURA, J.R.S. \& MÉIS, M.R.M. (1986) Contribuicão à estratigrafia do Quaternário superior no médio vale do rio Paraíba do Sul - Bananal, SP. An. Acad. bras. CL, 58:89-102.

MOURA, J.R.S. \& MELLO, C.L. (1991) Classificacão aloestratigráfica do Quaternário superior na região de Bananal (SP/RJ). Rev. Bras. Geoc., 21:236-254.

OBRUCHEV, V.A. (1948) Osnovnye cherty kinetiki i plastiki neotektoniki. Akad. Nauk. SSSR, Izv. Serv.Geol., 5:13-24.

PETIT, J.P. (1987) Criteria for the sense of movement on fault surfaces in brittle rocks. Journ. Struct. Geol., 9: 597-608.

RENNE, P.R.; ERNESTO, M.; PACCA, I.G.; COE, R.S.; GLEN, J.M.; PRÉVOT, M.; PERRIN, M. (1992) The age of Paraná Flood Volcanism, rifting of Gondwanaland, and the Jurassic-Cretaceous boundary. Science, 258:975-979.

RICCOMINI, C. (1989) O Rift Continental do Sudeste do Brasil. São Paulo, 256p. (Tese de doutoramento apresentada ao Instituto de Geociências da Universidade de São Paulo).

RICCOMINI, C. (1995) Tectonismo gerador e deformador dos depósitos sedimentares pós-Gondvânicos da porção centro-oriental do Estado de São Paulo e áreas vizinhas. São Paulo, 100p. (Tese de livre-docência apresentada ao Instituto de Geociências da Universidade de São Paulo).

RICCOMINI, C.; APPI, C.J.; FREITAS, E.L.; ARAI, M. (1987) Tectônica e sedimentação no Sistema de Rifts Continentais da Serra do Mar (bacias de Volta Redonda, Resende, Taubaté e São Paulo). In: SIMPÓSIO DE GEOLOGIA RJ-ES, 1, Rio de Janeiro. Anais. Rio de Janeiro, SBG, p. 253-298.

RICCOMINI, C.; PELOGGIA, A.U.G.; SALONI, J.C.L.; KOHNKE, M.W.; FIGUEIRA, R.M. (1989) Neotectonic activity in the Serra do Mar rift system (Southeastern Brazil). J South Am. Earih. ScL, 2:191-197. 
RICCOMINI, C; TURCQ, B.; SUGUIO, K. (1991a) The record of continental sedimentation in Southeastem Brazil during the last millennium: Paleoseismiticity, the little ice age, and man. An. Acod. bros. Ciênc., 63:90.

RICCOMINI, C.; COIMBRA, A.M.; SUGUIO, K.; MIHÁLY, P.; MATURANA, E.C. (1 991b) Nova unidade estratigrafica cenozóica da Bacia de Taubaté, SP: Formação Pindamonhangaba. Boi $1 G-U S P$, Publ.Esp., 9:141-150.

RIEDEL, W. (1929) Zur mechanik geologisher brucherscheinunge. Ein beitrag zum problem der "fiederspolten". Zentralbl. Minera., Geol. Paleont., 1929b:354-368.

RODRIGUEZ, S.K. (1993) Neotectônica e sedimentação quaternária na região da "Volta Grande" do Rio Xingu, Altamira, PA. São Paulo, 10Op. (Dissertação de Mestrado apresentada ao Instituto de Geociéncias da Universidade de São Paulo).

SAADI, A.; HASUI, Y.; MAGALHÃES, F.S. (1991) Informações sobre a neotectônica e morfogênese de Minas Gerais. In: SIMPÓSIO NACIONAL DE ESTUDOS TECTÔNICOS, 3, Rio Claro. Boletim. Rio Claro, SBG, p. 105-107.
SALVADOR, E.D. (1994) Análise neoteclônica da região do Vale do Rio Paraíba do Sul compreendida entre Cruzeiro (SP) e Itatiaia (RJ). São Paulo, 129p. (Dissertação de mestrado apresentada ao Instituto de Geociéncias da Universidade de São Paulo).

TURNER, S.; REGELOUS, M.; KELLEY, S.; HAWKESWORTH, C.; MANTOVANI, M. (1994) Majmatism and continental break-up in the South Atlantic: high precision ${ }^{40} \mathrm{Ar}-{ }^{39} \mathrm{Ar}$ geochronology. Earth Planet. Sei. Lett., 124:333-348.

ZUCHffiWICZ, W. (1991) On different approaches to neotectonics: a Polish Carpathians example. Episodes, 14:116-124.

Manuscrito A842

Recebido em 07 de março de 1996

Revisão dos autores em 17 de outubro de 1996 Revisão aceita em 20 de outubro de 1996 